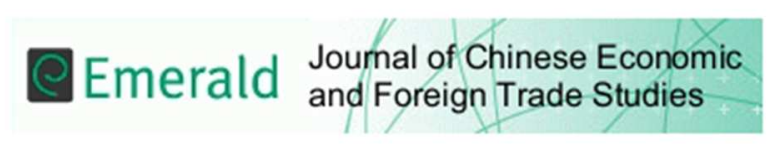

Structural Change in Industrial Output: China 1995-2010.

\begin{tabular}{|r|l|}
\hline Journal: & Journal of Chinese Economic and Foreign Trade Studies \\
\hline Manuscript ID & JCEFTS-12-2015-0031.R2 \\
\hline Manuscript Type: & Research Paper \\
\hline Keywords: & China, input-output, evolution, structure, decomposition, 1995-2010 \\
\hline \multicolumn{2}{|r}{} \\
\hline
\end{tabular}




\title{
Structural Change in Industrial Output: China 1995-2010
}

\begin{abstract}
$\underline{\text { Abstract }}$
The aim of this paper is to learn about some patterns of sectoral and industrial structural change of the Chinese economy over the 1995-2010 period. To such a purpose, we set up a quantitative methodology via input-output modelling, which allows us to decompose gross output into some key demand sources or contributions. It can be shown that the trajectory of the main structural patterns over the period were both not smooth and pretty unbalanced and that they generally responded to both domestic policy and international shocks. Export demand and heavy industry appeared to be the main engines of the economy, which showed massive increases in their share of output, at the expense of domestic demand, services and agriculture. Despite the high growth rates over this period, the Chinese economy seemed to be in need of rebalancing. There is however some indication towards the end of our period that the economy was starting to go that way.
\end{abstract}

Key Words: China, industrial structural change, input-output decomposition, trajectories over 1995-2010.

JEL Classification: L16, O4, B4, E2

1. Introduction

This paper is both a continuation of our quantitative study of structural change in China and a complement to our previous paper (Albala-Bertrand 2013). The latter focused on the structural change of important indicators such as capital productivity, capital intensity, participation rate and total factor productivity for China and its main regions, at an aggregate level. The present paper focuses on structural change at an inter-industrial level. For the purpose, we use a quantitative approach by means of a decomposition of the input-output model ${ }^{(1)}$. This model mostly relies on fix coefficients, so its use for forecasting beyond three-to-five years may make it insufficient in any case, let alone in a country undergoing extremely rapid economic and social changes. But this is not an issue for our purpose, as we use the model to assess what happened in the recent past, rather than to forecast the state of the economy in the future. To such an aim, we 
feed the model with the available input-output statistics with a view to assess the evolution of the industrial structure of China between 1995 and 2010, which is then significantly more than a mere accounting exercise. This is the period of the most momentous policy thrusts, and it is just about bounded by two international shocks, the Southeast Asian crisis of 1997 and the world crisis that started in $2007 / 8$.

There are many studies of structural change in China at different economic levels for similar periods. A good deal of them concentrates on exports (e.g. He and Zhang 2010, Amiti and Freund 2010, Feentra and Wei 2010), others do on employment (e.g. Cai and Wang 2010, Evans and Stavetieg 2009), and others on industrial productivity and change (e.g. Zheng, Wang and Shi 2008, Yueh 2011). A few have also used input-output analysis with its focus on inter-industrial relationships, such as Ichimura and Wang (2003), engaging in interregional analysis for a given years; Pan, Yang and Lin (2012) focusing on technological spillovers for three given years; Pei, Dietzenbacher et al. (2011) concentrating on an import growth decomposition over 1997-2005; Yang, Dietzenbacher et al. (2015) dealing with vertical specialization; and there are others that focus on the environment, energy and the like. The difference with them is that ours, first, use a different kind of decomposition that allows to differentiate consistently from various sources of output demand; second, we use tables for each year of our period (1995-2010), composed of 33 industries, and we show the structural change trajectory of demand sources, economic sectors and main industries over this period ${ }^{(1)}$.

Our main conclusions are that the main structural trajectories and patterns over the period were both not smooth and pretty unbalanced and that they generally responded to both domestic policy 
and international shocks. Export demand and heavy industry appear to be the main engines of the economy, which show massive increases in their share of output, at the expense of domestic demand, services and agriculture, which then show significant decreases in their share of output. So despite the high growth rates over the period, the Chinese economy seemed to be in need of rebalancing. There is however some indication that the economy was starting to rebalance by the end of our period.

The paper is structured as follows. We start by unravelling our methodology (2.), we then present our analysis and results for China in both an aggregate (3.1.) and a disaggregated fashion (3.2.) with the help of some useful charts, and then we show the structural evolution over the period by means of graph trajectories of economic sectors and their main sources of demand (3.3.). We finally present our main conclusions (4.).

\section{Methodology}

We analyze structural change by means of an empirical decomposition of input-output tables. This tradition started with Chenery (1960) and was later refined by several authors (e.g. Dervis et al., 1982; Kubo et al., 1986; Sakurai, 1990). The decomposition method used in this paper follows more closely Wyckoff and Sakurai (1992) and Albala-Bertrand (1999, 2006). This method of analyzing structural change, while exploiting most of the advantages of the inputoutput model, avoids most of its limitations (Bulmer-Thomas 1982; Ciaschini 1988), especially the standard shortcomings of forecasting on fixed coefficients for countries undergoing momentous economic and social changes, as we confine the analysis to yearly snapshots within our focus period (1995-2010). 
The overall structural change over a period can be decomposed into the demand sources contributing to such a change, both for the whole industrial complex and for each constituent industry. To be noticed, these sources are not be taken as explaining structural change in terms of causality, but only in terms of ex-post concomitance. Therefore, these are useful empirical foundations for explanatory sectoral and structural analyses, which is beyond the scope of this paper.

For presentational clarity, we split the method to assess structural change between the text and our appendix. So first, we describe the way we use the general input-output framework in the text and then we use the appendix to present the derivation leading to the decompositions of both output change and output share changes.

\subsection{The General Input-Output Framework}

Input-output tables or matrices are statistical tools that account for all the market transactions that any industry has in an economy, i.e. intermediate transactions with all classified industries and with its demand for final output. This accounts for the total gross output (i.e. intermediate and final) of an economy, disaggregated into industries and/or regions. It also account, at the level of each industry, for the cost of primary inputs or value added. So at the level of intermediate transactions, this gives rise to a symmetrical double-entry table or matrix that contains the same classified industries in both columns (intermediate demands) and rows (intermediate supplies). In addition, it provides another matrix for the final output supplies of all classified industries, and another for primary inputs. Let's then assume that we have available 
input-output matrices for a given economy for at least two years, i.e. a base year "0" and a comparison year "1." This would include the following matrices: an $n x n$ matrix $W$ of intermediate demands for the domestic and imported inputs of all the $n$ classified industries; an $n$ $x m$ matrix $F$ of output for domestic final demands from the same industries, including both domestic and imported commodities; an n x 1 vector $E$ of exports from the same industries; an $n$ $x n$ matrix $M^{W}$ of intermediate import usage of all industries; and an $n x m$ matrix $M^{F}$ of imports of final goods and services. Hence, the $\mathrm{n} \times 1$ domestic gross output vector $X$ of the $n$ industries will be given by:

$$
X=W i+F i+E-M^{W} i-M^{F} i \quad \text { (domestic gross output) }^{(2)}
$$

Where $i$ is an $n \times 1$ unity vector.

So let $a_{i j}$ represent the input from the $i^{\text {th }}$ industry that is required by the $j^{\text {th }}$ industry to produce one unit of its output at a given moment, which in terms of standard technical coefficients is: $a_{i j}=W_{i j} / X_{j}$ This therefore generates an $\mathrm{n} \times \mathrm{n}$ matrix $A$ of coefficients, or rearranging:

$$
A X=W i
$$

Substituting (2) into (1):

$$
X=A X+F i+E-M^{W} i-M^{F} i
$$

We then calculate the proportion of imported inputs in total inputs $\left(\mathrm{m}^{\mathrm{W}}\right)$ and imported final goods/services in total final goods/services $\left(m^{F}\right)$, which at the level of each cell would be $m^{W}{ }_{i j}=$ $M_{i j}^{W} / W_{i j}$ and $m^{F}{ }_{i j}=M_{i n}^{F} / F_{i n}$, respectively. So $M^{W}=m^{W} * W$ and $M^{F}=m^{F} * F$. Then, we have:

$$
M i=M^{W} i+M^{F} i=m^{W} * W i+m^{F} * F i=m^{W} * A X+m^{F} * F i
$$

The asterisk (*) and the stroke (“/”) indicate that the multiplication and the division are standard scalar rather than a matrix multiplication and division, respectively ${ }^{(3)}$. Then substituting (4) into (3) and factoring: 


$$
X=\left([i]-m^{W}\right) * A X+\left([i]-m^{F}\right) * F i+E
$$

Where $[i]$ is an $n \times n$ unity matrix, i.e. a matrix with a number 1 in each of its cells.

Let's make $U^{W}=\left([i]-m^{W}\right)$ and $U^{F}=\left([i]-m^{F}\right)$. Notice that these two matrices provide the ratios of domestic-to-total intermediate demands and domestic-to-total final demands, respectively. They can be interpreted as indicators of import substitution. Then equation (5) becomes:

$$
X=U^{W} * A X+U^{W} * F i+E
$$

Therefore, solving for $X$, we obtain the input-output model:

$$
X=\left(I-U^{W} * A\right)^{-1}\left(U^{F} * F i+E\right)
$$

Where " $I$ " is the identity matrix. Let's also drop the unity vector " $i$ ", which post multiplies $F$, as we will be working with the totals only, i.e. $F$ becomes an $\mathrm{n}$ x 1 vector, so $M^{F}$ does too. Notice that the first term on the right-hand side is the Leontief inverse for domestic intermediates only, and represents coefficients or weights, while the second term contains final domestic output for domestic and foreign demands, and represents volumes. In order to use less notation, let $B=\left(I-U^{W} * A\right)^{-1}$ and $G=\left(U^{F} * F+E\right)$. Then the input-output model becomes:

$X=B G$

From here two decomposition can be produced: one for gross output growth rate and one for output share changes (see Appendix for derivations). Each of the five terms below, in terms of variation or growth rate (i.e. absolute growth $(\Delta X)$ or its growth rate $\left.\left(X^{-1} \Delta X\right)\right)$ represents the demand contribution to the gross output of the economy, and has the following meanings:

(i) $B_{0} U_{0}^{F} * \Delta F \quad$ contribution of final domestic demand expansion $(F D E)$;

(ii) $B_{0} \Delta E \quad$ contribution of export demand expansion $(E D E)$;

(iii) $B_{0} \Delta U^{F} * F_{1} \quad$ contribution of import substitution of final goods/services $(I S F)^{(4)}$; 
(iv) $B_{0} \Delta U^{W} * W_{1} i \quad$ contribution of import substitution of intermediate inputs (ISW);

(v) $B_{0} U_{0}^{W} * \triangle A X_{1}$ contribution of changes in input-output coefficients $(\text { IOC })^{(5)}$.

In turn, the decomposition for gross output share changes has an analogous meaning to the above, but refers to the absolute value of the share change $(\delta X)$ and the relative share change in percentage points $\left(\delta X / X_{t 1}\right)$. As shown in the appendix, the last three terms are exactly the same as above, while (i) and (ii) now become $B_{0} \hat{\mathrm{U}}_{0}^{\mathrm{F}} * \delta F$ and $B_{0} \delta E$, respectively. To recall, these demand contributions should not be taken as explaining structural change in terms of causality, but in terms of concomitance, as these are the result of complex interactions of domestic policies and endogenous dynamics, and world trends and shocks. These factors are beyond the scope of this paper, but our analysis of contributions may serve as a basis for such a type of aims.

\subsection{Application to China}

For the purpose, we produce both a 33-industry disaggregation and some relevant subgroupings. The analysis focuses on the 1995-2010 period. The source data comes from both the World Input-Output Database (WIOD) and the National Bureau of Statistics of China (NBS). WIOD input-output tables were available in dollar terms for current (1995-2011) and previous year (1996-2009) basic prices ${ }^{(6)}$. The latter tables were used to derive implicit price indexes to deflate the current-price series, at an industrial level. Additional prices for 2010 and 2011 were obtained from the National Bureau of Statistics of China (NBS). The latter has only produced tables for four given years with 23 comparable industries (1997, 2000, 2005 and 2010), which were used as a general check. But we prefer WIOD tables as they seem to be more consistent, with a full 
public documentation of the methodology used (see WIOD). Given our purpose, we transformed the tables into constant Yuan prices of 1995. In addition, to secure further consistency and stability, we calculated a 3-year moving average of the tables for all the period. Not having available a 1994 table for a 3-year average for 1995, we decided to keep the 1995 table as a single year, as this is the base year for the constant series. So our series go from 1995 to $2010^{(7)}$.

\section{Analysis of Results}

The analysis below is divided into three parts. Firstly, we analyzed the change between 1995 and 2010 for aggregations of primary, secondary and tertiary sectors. Secondly, we disaggregate such sectors into some key constituent industries to show how they evolved and contributed to the aggregation. And thirdly, we look at the trajectory of changes of these sectors, and some of their main industries, year after year from 1995 to 2010 (see note 6).

\subsection{Aggregate Analysis}

Table No.1 is divided into two panels: the left panel shows the change in the shares $\left(\delta X / X_{2010}\right)$ of gross output $(X)$, while the right panel shows the growth rates $\left(\Delta X / X_{1995}\right)$ of gross output $(X)$ for the 33 disaggregated industries, and for grouped ones into customary sectors, between 1995 and 2010. The share-change panel is expressed in percentage points (pp), while the growth-rate panel is expressed in percentage $(\%)$.

Table No. 1

ABOUT HERE 
The first column in the shares panel presents the share changes in gross output, expressed in percentage points of 2010. The following five columns: FDE, EDE, ISF, ISW, and IOC, are the demand sources or contributions to such share changes, expressed in percentage points (pp), so that for each industry the addition of the contributions add up to its share change. In turn, the first column in the growth panel presents the growth rates of gross output, expressed in percentage $\left(\Delta X / X_{1995)}\right)$ The five demand contributions are however expressed in percentage points so that their addition amounts to the growth rate in question. The meaning of each of these five terms is as indicated above.

The final two column in the shares panel expresses the share of each sector in gross output in the initial year $\left(S_{1995}\right)$ and final year $\left(S_{2010}\right)$, respectively. In addition, the bottom section regroup the industries in the standard categories of primary, secondary and tertiary sectors, with its main constituent industries. Finally, the bottom row presents the column sums (shares panel) or the column weighted averages (growth panel). Let us then start with the whole economy and then concentrate on the three economic sectors.

The sum total of the first column of the shares panel has to add to zero, indicating that some industries grew faster than average, producing a positive share change, while others grew slower than average, exhibiting a negative share change. For the whole economy, only the contribution of final domestic demand $(F D E)$ was negative, amounting to a massive contraction of 20 percentage points over the period. All the other contributions are positive, especially that due to foreign demand expansion $(E D E)$ and also to the increase in mutual input demands of the economy, producing a positive change in input-output coefficients (IOC). Imported input and 
final output substitutions (ISW and ISF) also played a positive, but secondary role. The growth panel, bottom line, shows that the final domestic demand is the larger contributor to the total growth of gross output over the period ${ }^{(8)}$, but it lost 20 percentage points (pp) in its share of gross output, while the foreign demand contribution increased its share by 8 percentage points. This is because the growth rate of the former has systematically been below the economy average growth rate of $385 \%$, while the latter has systematically been above it, namely $272 \%$ and $568 \%$, respectively (not shown in the table). This simply confirms that the economy has moved strongly towards exports and investment (530\%) at the expense of domestic consumption, which grew by only $200 \%$ (not shown in the table). Notice however that the growth rate over the period was very high, and the growth rates for each of our industries were positive, so share losses should not be interpreted as losses in the growth of absolute values, but only in relative terms.

\subsection{Disaggregated Analysis}

The aggregate results above can be disaggregated into the standard main sectors of the economy and some key industries within them. The bottom blocks of both panels of Table No.1 show this for primary, secondary (including construction) and tertiary sectors. The last column of the shares panel shows the shares at the end of the period. It shows that the secondary sector share grew from $60 \mathrm{pp}$ to $75 \mathrm{pp}$, and notably heavy industry more than double its share, from $14 \mathrm{pp}$ in 1995 to a massive 32pp in 2010. Except for "Post and telecommunications" (No. 26) and a few members of light industry, all the other industries lost share presence in gross output. Chart 1 below gives a synoptic view of the share change over the period for this categorization. 


\section{Chart 1 \\ ABOUT HERE}

The secondary sector increased massively its share in gross output at the expense of especially the primary sector, but also the tertiary one. This hides the very fact that the secondary sector increase was mostly due to heavy industry (17.6pp) at the expense of light, medium and construction industries. And as shown in Table No.1, within heavy industry, the increase was especially due to "Electrical and optical equipment" (No.14) and "Transport equipment" (No.15), increasing their share by $11.1 \mathrm{pp}$ and $3.3 \mathrm{pp}$, respectively.

In turn, the fall in the primary sector share is mostly due to the non-mining primary sector (No.1), which fell by $8.6 \mathrm{pp}$, while Mining and quarry fell by $1.6 \mathrm{pp}$. As regards the tertiary sector, the main fall in share was due especially to domestic wholesale trade and financial intermediation (Nos.19, and 27), with a slight positive direction by especially Post and telecommunications (No.26). Chart 2 helps us visualize the five demand contributions to the sectoral share changes above.

Chart 2

ABOUT HERE

The contribution of domestic demand $(F D E)$ fell in all sectors, while that of export demand expansion $(E D E)$ strongly increased in the secondary sector and to a minor degree in the tertiary one. The other positive contribution is that to direct input-output coefficients (IOC) from the secondary sector, meaning that this sector pull on the whole economy has significantly increased. This sector also shows an increase in import substitution of especially intermediate inputs (ISW) 
and to a much lesser extent of final goods (ISF), which means that a higher proportion of intermediates inputs is produced domestically.

Table No.1 shows that all the above contributions to the secondary sector are mostly from heavy industry, notably those to foreign demand $(E D E)$ and input intermediation coefficients $(I O C)$. The latter is especially marked from the same heavy industries mentioned above, but also from No.13 Machinery. Medium industry shows positive contributions to especially export demand and import substitution, but negative ones to domestic demand and input-output coefficients. Light industry, in turn, shows also positive contributions to both types of import substitution, (especially from No. 4 "Textiles"), and input-output coefficients (particularly from No.3 "Food beverages and tobacco"). This is an indication of higher domestic reliance, and probably higher technical sophistication, in these areas. The opposite happens in the primary sector, where all contributions are negative or null, except for a slim positive contribution to imported input substitution from the non-mining primary sector (No.1). The tertiary sector is more mixed, as foreign demand and both items of import substitution show positive contributions, especially from domestic trade and financial activities.

The growth panel (bottom block) shows the story in growth terms. The secondary sector shows an unweighted growth rate of 508\%, well above the total average of the weighted growth rate of $385 \%$, while the other sectors were well below such an average, especially the primary sector. The heavy industry within the secondary sector grew (unweighted) by a massive $985 \%$ over the period, especially on account of No.14 Electrical and optical equipment. For all sectors, the main contributors to their growth rates are domestic and foreign demands ( $F D E$ and $E D E)$, the latter 
especially strong for heavy industry, which also shows an important growth in both input substitution (ISW) and input intermediation (IOC), mostly in the said industry No.14, but also in No.15 Transport equipment. The tertiary sector shows also gains in both items of import substitution.

\subsection{Structural Evolution over the Period}

In this section, we show how the results above built up over the 16-year period, by graphically presenting the changes above in terms of periods made of two consecutive years, from 1995-96 to 2010-11 (see note 9), and showing that main policy reforms and world shock can help explain such evolution. But first a fast look at the trajectory of growth rates of gross output. Graphs 1 shows the growth rate trajectory of the economy and its main sectors, presenting a clear slowdown over 1996- 2000 for the three sectors, an acceleration over the 2000-2006, especially on the back of the secondary sector, then a fast slowdown over 2006-2009 for all sectors and a recovery afterwards for especially the secondary and tertiary sectors. This changes in the patterns of growth rates have clear effects in the patterns of structural change via the changes in the shares of sectors and industries in total gross output over the full period, as is shown in the next two subsections.

Graph 1

ABOUT HERE

(i) Sectors and subsectors makeup 
Graph 2 below presents the evolution of the share change of the three economic sectors. The secondary sector gained share all over the period (curve over the 0.0 axis), while the primary one did the opposite (curve under the 0.0 axis), and the tertiary sector was for the most part losing representation. For example, in the period 1998-99, both secondary and tertiary sectors gain share at the expense of the primary sector, while in 2005-06 the secondary sector gains share at the expense of the other two sectors ${ }^{(9)}$. The curve trajectories are however not smooth, showing important changes in certain periods, especially for the secondary sector, which shows increasing share gains in gross output from 1998 to 2007, notably between 2000-01 and 2006-07, reaching a peak in 2005-06. From this peak onwards there is a fast descent in the strength of percentage point gains, but is still on the positive side, so it keeps gaining share but at a slower pace. In turn, the tertiary sector is mostly on the negative side, almost mirroring the secondary one, except for the period 1997-2000 and from 2009.

Graph 2

ABOUT HERE

Lastly, the primary sector is all along on the negative side, showing its biggest losses of share over the period 2000-07. These patterns can be better informed by presenting the trajectory of the sub-sectoral components of each of the main sectors so as to show their impact on the sectoral patterns of Graph $2^{(10)}$. Graph 3 shows the secondary sector disaggregated into light, medium, heavy and construction industries.

Graph 3

ABOUT HERE 
The thick curve (with a glow) is again the secondary sector as in Graph 2, while the other curves are its main sub-sectoral components. The most striking point here is that almost all of the secondary sector pattern is due to the trajectory of heavy industry, while the heavy industry pattern itself is mostly explained by the "Electrical and optical equipment" industry (No.14), which follows a similar trajectory, picking in 2004-05 (not shown in graph). At a more unstable and less salient levels, transport equipment (No. 15), utilities (No. 17) and non-electrical machinery (No. 13) also contribute to this pattern (not shown in graph). Graph 4 shows the same for the tertiary sector, which is disaggregated into domestic trade, transport, finance and social sectors. The fall in tertiary sector share in gross output, especially between 2001 and 2008, seems to be mostly due to falls in domestic trade and finance, and at a slower level social sectors.

Graph 4

ABOUT HERE

On the other hand, most of the positive share changes of the tertiary sector seem to be due to transport services, especially up to 2000-01 and from 2008-09. Notice, however, that a curve trajectory close to the 0.0 line means a pretty high growth rate, just about the (unweighted) average of the economy ${ }^{(11)}$.

\section{(ii) Demand Contributions}

Graph 5 presents the trajectory followed by the five demand contributions over the period. The top contribution to the total share change is due to export demand expansion $(E D E)$, notably between 2000 and 2006, mostly at the expense of domestic demand expansion (FDE). The latter shows a systematic negative contribution to its share change until 2007-08, when start regaining 
ground at the expense of $E D E$, reverting some of the lost ground, but at decreasing rates, as it seems that by 2011 the two curves go in opposite directions again.

\title{
Graph 5 \\ ABOUT HERE
}

As regards the other three contributions, there is some slow and unstable contribution from import substitution of final goods (ISF) and a more significant imported input substitution (ISW) between 2005 and 2010. The contribution of input-output coefficients (IOC), indicating strength of mutual demands for domestic output, appears mostly positive, but at low percentage point levels

Lastly, Graph 6 is a collection of five subgraphs that show the sectoral share change trajectory of each of the five demand contributions $F D E$ (final demand), $E D E$ (foreign demand), ISF (final import substitution), ISW (imported input substitution) and IOC (domestic input-output intermediation) for the primary, secondary and tertiary sectors of the economy.

\section{Graph 6 \\ ABOUT HERE}

\begin{abstract}
The primary and tertiary sectors show a similar trajectory for each of the five contribution, except for $I S F$, and these are near but mostly under the 0.0 percentage point (pp) change, especially for the primary sector. This tallies with the total pp change for these two sectors over the full period, as shown in Table No. 1 (i.e. the primary sector lost $10.3 \mathrm{pp}$ while the tertiary one
\end{abstract}


4.9pp). For $I S F$, the latter appears as first losing pp ground (up to 2001-02) and then regaining it (mostly from 2002-03 onwards).

The Secondary sector however shows a more variable pattern, being mostly and strongly on the positive side. Domestic demand $(F D E)$ and external demand $(E D E)$ appear to show an about mirror pattern (i.e. as $E D E$ increases, $F D E$ falls and vice versa). This simply means that most of the positive share change in the secondary sector has been due to $E D E$ mostly at the expense of $F D E$, and vice versa after 2007-08, when $E D E$ has its deepest fall. For $I S W$, this sector shows a positive contribution between 2005 and 2010, peaking in 2007-08. In turn, IOC shows a positive pattern all along except for the period 2009-11. Finally, ISF shows a similar trajectory for both secondary and tertiary sectors, being negative between 1998 and 2003 and positive between 2003 and 2011, with a dive in 2008-09. This tallies with the massive gain by the secondary sector in the share of gross output over the full period (i.e. 15.2pp). Given that most of the inflection points happen after 2006-07, then this also shows that the international crisis and policies therein had an important impact on the China economy, as further detailed below.

\subsection{Phases, World Shocks and Policies}

The patterns of Table No.1, charts and graphs above respond mostly to domestic policy, domestic dynamics and world conditions. Table No.2 shows the main phases and features of the structural change which can generally be visualized by means of our graphs above. So this table also acts as a guide to our graphs. 
Table No. 2

ABOUT HERE

The 1997 East Asian crisis put a slowdown to exports gains and, among other explanations, sluggish rural income growth and widespread industrial inefficiency that impinged on significant falls in the total factor productivity of the economy (Albala-Bertrand 2013, Yueh 2013, Zhen, Bigsten and $\mathrm{Hu} 2009$ ). At the time, some reforms were introduced to face the crisis, adopting policies to stimulate domestic demand, especially via construction and services development. These came on top of important reforms introduced over the period 1994-96 that aimed at both a nation-wide liberalization of capital inflows to attract foreign direct investment and a massive push towards privatization to develop private domestic business (Prasad and Wei 2005).

Between 1997 and 2001, there were further reforms especially via a law that let the markets to set or guide prices with outside intervention by the government. In addition, in 2001 China became a member of the WTO, which forced a policy of eliminating direct price controls and export subsidies to agricultural products (Yueh 2010, 2013; Zhang and Tan 2007, OECD 2002). All these plus other associated reforms, like open market agreements with the US and Southeast Asian countries, created the strong platform on which capital intensity and total factor productivity contributed to the very high growth rates of the economy, especially between 2001 and 2007 (Albala-Bertrand 2013). This especially relied upon heavy industry and exports (Yueh 2010, 2011; Lardy 2006), as also reflected in Graph 3 and Graph 5 above. By 2007, China officially acknowledged that its economic growth was "unsteady, unbalanced, uncoordinated and unsustainable" (Wen Jiabao-Annual Meeting of China's legislature, 2007), which is what our Table No.1, charts and graphs reflect. To be sure, this reality check did not just referred to the situation between domestic and foreign demand, and between the secondary and the other 
economic sectors, but also about regional disparities, income inequalities, and market and product fragmentation, among others problems (Goodman and Parker 2014, Yueh 2010, Zhang and Tan 2007, World Bank 2005, Fu 2004, Chow and Li 2002).

This official admission coincided with the onset of the international financial crisis (or Great Recession). This brought new policies to counteract it, especially via a massive stimulus package for agriculture, construction and services, with a special focus on housing and rural infrastructure, education and health, environment and disaster reconstruction, industry and transportation, tax cuts and finance, and so on (Wong 2011). This is well reflected in Graph 5 and the Graph 6 collection, as there appeared to have been a strong, but short lived, structural change reversal, especially from 2007, between final domestic demand expansion $(F D E)$ and external demand expansion $(E D E)$. This is also reflected in an important domestic substitution of previously imported intermediaries (ISW) and in an increasing domestic input intermediation (IOC). In terms of sectoral share change, as shown in Graph 2, the tertiary sector starts to reduce its losses and achieves gains after 2008, with a recovery of domestic retail and transport (see Graph 3), while the primary sector keeps losing share representation, but at lower levels.

So, over the period 1995-2011, world and regional international crises, counter and strategic policy packages, and the overall structural change of economy and society, can be generally illustrated with the help of the above analysis, which can complement and serve as the basis for other approaches and aims (e.g. He and Zhang 2010, Cai and Wang 2010, Zheng, Wang and Shi 2008). 


\section{Conclusions}

The aim of this paper was to learn about some patterns of sectoral and industrial structural change of the Chinese economy over the 1995-2010 period. To such purpose we set up a quantitative methodology via input-output modelling, which allowed us to decompose gross output into its main demand sources or contributions. Noting that the national output growth rates were around $10 \%$ over the period, and that on the whole these rates were positive for all sectors and industries, the main observations about structural change are as follows.

(i) Between 1995 and 2010, there was a significant structural change in favour of the secondary sector, and especially its heavy industry. This sector increased its share in gross output by over $15 \mathrm{pp}$ (pp: percentage points), from $60 \%$ to $75 \%$. Two thirds of this change was done at the expense of the primary sector (notably its non-mining industries), which lost over 10pp share in output, and one third at the expense of services (notably domestic trade and financial intermediation).

(ii) The main demand sources that contributed positively to the changes above were export expansion EDE (representing 8pp) and increases in domestic input intermediation IOC (7pp), and at a secondary level import substitution of both final goods ISF and industrial inputs ISW (1pp and 3pp, respectively). In turn, the main negative contribution comes from domestic demand, which lost 20pp share over the 
period. The latter loses come from all sectors, except for some industrial components of heavy industry (machinery, electrical, optical and transport equipment) and also post and telecommunications of the tertiary sector.

(iii) The above structural change, however, was not linear. The secondary sector, mostly pulled by its heavy industry, has most of its massive share gain over 2001 and 2007. That is between just after the 1997 East Asian crisis together with the liberalization of capital flows plus (guided) market prices, among other opening trade policies, and just before the Great Recession and some policies to rebalance the economy. It is not until 2009 that the tertiary sector appears to regain slightly some of its lost share in output, while the primary sector keeps losing representation, but at lower levels.

(iv) As regards demand contributions, export demand expansion (EDE) and domestic demand expansion (EFE) show an almost mirror trajectory, while the former has a massive share gain the latter shows a massive share loss. From around 2007, for the first time the share change of export demand becomes negative and falls below that of domestic demand, the latter even exhibiting a positive share gain from around 2008 for the very first time in the observed period. But it seems that by 2011 , the two contributions start to revert again. To be also noticed, there is a significant increase in the share of final and input imported substitution from 2005. This, together with the general increase of domestic intermediate input-output trade (IOC), may be an indication of an economy that moves to a more endogenously sustainable one, which is part of the necessary rebalancing of the Chinese economy. 
As shown in the text, all these patterns and trajectories can be generally shown to respond to both international shocks and main domestic policy decisions. Whether the Chinese economy will properly rebalance, as the need for it has been acknowledged by the government, will mostly depend on policies that can sustain a stable growth in which domestic demand, especially consumption, becomes the main contributor to it. The recent decrease in growth rates puts additional pressures and difficulties to achieve such a rebalancing. But there are recent indications that consumption is taking a greater role in the dynamics of China's economic growth (World Bank 2015, 2014; The Economist 12/09/2015). 


\section{Notes}

(1) A regional disaggregation of inter-sectoral relationships would have been useful, but there are no systematic regional input-output tables for China. To further clarify, as is well known, input-output analysis is a demand rather than supply type of analysis, so apart from the technology related to the combination of intermediates used by each sector/industry, which is specified in the matrices of direct coefficients, there is no focus on embodied or disembodied technology, as in supply studies (see Albala-Bertrand 2013). Neither are there input-output tables that directly include the import content of exports at sectoral/industrial level, so in our paper this is treated by means of imported input substitution of the whole economy, which does not allow to distinguish between intermediate imports used for domestic demand (consumption and investment) and those for export demand. Given the highly globalized fragmentation of some industrial structures, the import content of exports and their supply chains, which relates to vertical specialization and derived value chains, are important research efforts, which have so far shown only relative successes. Given the insufficiency of direct information from the standard tables, this issue has been tried indirectly either via the use of some strong assumptions (e.g. Hummels et al. 2001), which produce some significant biases, or by means of complementary data that comes from custom and tax rules peculiar to China alone (Yang, Dietzenbacher et al. 2015), which also require some convenient assumptions on these data, so the results may not be devoid enough of biases. This is not what our paper is about, but the research attention paid to this issue is an important endeavour, which will surely see more robust results in due course.

(2) Notice that gross output includes both intermediate and final output, so from the viewpoint of GDP it would be double counting, as GDP already contains all the value-added additions to final output from all the intermediate inputs required for its production. But from the 
viewpoint of each industry (or firm), it represents the actual productive effort to supply both intermediate inputs to other industries (or firms) and goods/services for final demands. So what the input-output model does is to show the total productive effort that, directly and indirectly, all sectors of the economy have to undergo to satisfy the production of one unit of final output of a particular sector or industry. This represents one unit of value added for the economy, which would be distributed among all the many participating sectors, as they have to pay their productive factors for the effort to satisfy that unit of final demand. This productive effort would normally be significantly more than one unit of final output, and can be derived from the inputoutput multipliers associated with the Leontief inverse. The decomposition that we use here derives from the full input-output model and cannot be possibly produced by focusing on final output alone. To do so would ignore the actual inter-industrial effort required to secure such one unit of final output. And this is the very basic advantage of approaching the economy via inputoutput analysis (see for example Bulmer-Thomas 1982, Eurostat 2008).

(3) In previous studies, imports were treated as if each industrial import was to be used by all industries in the same proportion, as normally only the total input usage, at the level of each industry, was available, i.e. the composition of imported inputs in the output of each industry was not known. But given that we have the full import tables for China, we use the full table in our calculations, which is why we have to use scalar multiplication for the purpose. In other words, $m^{W} * W$ means that each cell of $W$ is multiplied by the same cell of $m^{W}$. So $M^{W}$ is the matrix of imported inputs.

(4) Terms (iii) and (iv) are positive when there is an increase in import substitution over the period i.e. an increase in the proportion of domestic inputs in total inputs and domestic final 
output in total final output, respectively. This represents a variation in demand exclusively due to variations in import substitution.

(5) This represents the change in demand over the period, exclusively due to the Leontief weighted variation of direct (domestic) input-output coefficients of the system. If this term is positive for a particular industry, then this means that more of the output of this industry is used as input for the production of other industries than in the base year. That is, it represents an increase in the direct domestic contribution of this industry towards the system. Hence, it represents a version of direct backward domestic linkages (demand) from the rest of the economy to this industry, or alternatively a version of the direct forward domestic linkage (supply) of this industry towards the rest of the economy over the period (Hirschman, 1977).

(6) As the OECD defines it: "the basic price is the amount receivable by the producer from the purchaser for a unit of a good or service produced as output minus any tax payable, and plus any subsidy receivable, on that unit as a consequence of its production or sale. It excludes any transport charges invoiced separately by the producer as well as suppliers' retail and wholesale margins". This is considered a better measure of industrial efforts than market (final) prices.

(7) We also add the change over the period 2010-2011. The latter is only used for illustration, but not as a 3-year average, as we have no data for 2012.

(8) Given the input-output model in equation (7), the total final demand (domestic and foreign) has to be the larger contributor to gross output, but not necessarily in growth or percentage points variation terms. The absolute change decomposition allows us to assess the size of such contributions plus the contributions from the other three factors over the period. 
(9) Recall that for each period, the percentage point sum of the three curves has to add to zero. And also that percentage points on the positive side implies that the sector is growing faster than the average growth of the economy (as measured by gross output), while the opposite is the case with negative percentage points. So we will not clutter this analysis with graphs about growth rates, as we are focusing on structural (share) changes.

(10) The primary sector is mostly "Agriculture, hunting, forestry and fishing" (No.1), as "Mining and quarrying" (No.2) plays a very secondary role. So the trajectory is just about the one in Graph 2, which is why we don't present an individual graph for this sector alone. Also notice that for each given period, the percentage point sum of the subsectors has to add up to the value of their sector.

(11) For example post and telecommunications (No. 26), which is part of "Transport plus", grew over the 15 year period by a massive $1036 \%$, as shown in Table No. 1 . But given that it started at very low share level, it looks less impressive in terms of the weighted average of the economy. "Education", and "Health \& social work" (Nos. 32 and 33), part of "Social Sectors", show also an impressive (unweighted) growth rates (327\% and $402 \%$, respectively), but given their low shares to start with, they don't seem to have made share improvements in total gross output, if anything the opposite. This is similar for industries of the other sectors, especially those of the primary one, which lost a significant share of the economy, but grew at positive but low rates all along, except for the period 2006-08, when it fell by around $3.5 \%$ (only industry No.1: non mining primary sector).

(12) The decomposition of the RHS first-term of equation (12) is as follows:

$B_{0} \Delta G=B_{0}\left\{\left[U_{1}^{F *} F_{1}+E_{1}\right]-\left[U_{0}^{F *} F_{0}+E_{0}\right]\right\}=B_{0}\left\{U_{1}^{F * F_{1}}-U_{0}^{F *} F_{0}+E_{1}-E_{0\}}\right\}=$ $B_{0}\left[U_{1}^{F} * F_{1}-U_{0}^{F *} F_{1}+U_{0}^{F} * \Delta F+\Delta E\right]=$ $B_{0}\left[\Delta U^{F} * F_{1}+U_{0}^{F * \Delta F+\Delta E]}\right.$ 
(13) The decomposition of the RHS second-term of equation (13) is as follows:

$\Delta B_{0} G_{1}=\left[B_{0} B_{0}^{-1} B_{1}-B_{0} B_{1}^{-1} B_{1}\right] G_{1}=B_{0}\left[B_{0}^{-1}-B_{1}^{-1}\right] B_{1} G_{1}=B_{0}\left[B_{0}^{-1}-B_{1}^{-1}\right] X_{1}=$ $B_{0}\left\{\left[I-U_{0}^{W} * A_{0}\right]-\left[I-U_{1}^{W} * A_{1}\right]\right\} X_{1}=B_{0}\left\{U_{1}^{W} * A_{1}-\left(U_{0}^{W} * A_{1}-U_{0}^{W} * A_{1}\right)-U_{0}{ }^{W} * A_{0}\right\} X_{1}=$ $B_{0}\left\{\Delta U^{W} * A_{1}+U_{0}^{W *} \Delta A\right\} X_{1}=B_{0}\left[\Delta U^{W} * A_{1} X_{1}+U_{0}{ }^{W} * \Delta A X_{1}\right]=$ $B_{0}\left[\Delta U^{W} * W_{1} i+U_{0}^{W *} \Delta A X_{l}\right]$

(14) The Paasche calculation would have led to the following result for equation (21): $\delta X=B_{1} U_{1}^{F} * \delta F+B_{1} \delta E+B_{1} \Delta U^{F} *\left(1+g_{a}\right) F_{0}+B_{1} \Delta U^{W *}\left(1+g_{a}\right) W_{0} i+B_{1} U_{l}^{W} * \Delta A\left(1+g_{a}\right) X_{0}$ 


\section{References}

Albala-Bertrand, J.M. (1999), 'Structural Change in Chile: 1960-1990,' Economic Systems Research, 11, 301-319.

Albala-Bertrand, J.M. (2006) "Changes in Chile's Production Structure, 1986-1996: Output and Industrial Interdenpendence", Cepal Review No.88, pp. 159-172

Albala-Bertrand, J.M. (2013) "Evolution of structural indicators: China and its regions 19812010”, Journal of Chinese and Foreign Trade Studies, Vol.6, No.3, pp.100-18.

Amiti, M. and Freund, C. (2010), "The Anatomy of China's Export Growth" in R.C. Feenstra and S.-J. Wei (Eds) (2010), China's Growing Role in World Trade (Chicago: University of Chicago Press), Chap2, pp.35-56.

Bulmer-Thomas, V. (1982), Input-Output Analysis in Developing Countries, John Wiley, New York.

Cai, F. and Wang, M. (2010) "Growth and structural changes in employment in transition China”, Journal of Comparative Economics Vol. 38, pp. 71-81.

Chenery, H. and Syrquin, M. (1986), 'Typical Patterns of Transformation', in H. Chenery,

Chenery, H. and Syrquin, M. (1986), 'Typical Patterns of Transformation', in H. Chenery,S. Robinson and M. Syrquin (Eds.) Industrialization and Growth (N.Y., OUP), Oxford University Press, Oxford, pp. 37-83.

Chow, G. and Li, K.W. (2002) "China's Economic Growth: 1952-2010”, Economic Development and Cultural Change, Vol. 51, No. 1, pp. 247-56.

Ciaschini, M. (Ed.), (1988), Input-Output Analysis: Current Developments, Chapman and Hall, London.

Dervis, K., de Melo, J. and Robinson, S. (1982), General Equilibrium Models for Development Policy, Cambridge University Press, Cambridge.

Dietzenbacher, E and Los, B. (1998), 'Structural Decomposition Techniques: Sense and Sensitivity', Economic Systems Research 10, 307-323.

Evans, P. and Stavetieg, S. (2009). "The Changing Structure of Employment in Contemporary China." IRLE Working Paper No. 190-09. http://irle.berkeley.edu/workingpapers/19009.pdf. 
Fu X., (2004), "Limited linkages from growth engines and regional disparities in China", Journal of Comparative Economics, No. 32, 148-64.

Goodman, M. and Parker, D. (2014) "China's Economic Policymaking at a Time of Transition", Center for Strategic and International Studies (April),

He, D. and Zhang, W. (2010) "How Dependent Is the Chinese Economy on Exports and in What Sense Has its Growth Been Export-Led?" Journal of Asian Economics, Vol. 1, No.21, pp. 87-104.

Hummels, D., J. Ishii and K.-M. Yi (2001) "The Nature and Growth of Vertical Specialization in World Trade". Journal of International Economics, No. 54, pp. 75-96.

Ichimura, S. and Wang, H.-J. (2003) Interregional Input-output Analysis of the Chinese Economy (London: World Scientific Publication).

Kubo, Y., de Melo, J., Robinson, S. and Syrquin, M. (1986), 'Interdependence and Industrial Structure', in H. Chenery, S. Robinson and M. Syrquin (Eds.) Industrialization and Growth, Oxford University Press, New York, pp.188-226.

Lardy, N. (2006) “China: Toward a Consumption-Driven Growth Path", Institute for International Economics, Policy Brief 06-6 (October).

NBS (National Bureau of Statistics of China): http://www.stats.gov.cn/english.

OECD (2002) China in the World Economy. The Domestic Policy Challenges (Paris, OECD).

Pan, W., Yang, D. and Lin, M. (2012) "Inter-industry Technology Spillover Effects in China: Evidence from 35 Industrial Sectors”, China \& World Economy, vol. 20, Issue 2, pp. 2340 ,

Pei, J., Dietzenbacher, E., Oosterhaven, J. and Yang, C. (2011), "Accounting for China's import growth: a structural decomposition for 1997 - 2005," Environment and Planning, vol. 43 (12), pp. 2971-299.

Prasad, E. and Wei, S. (2005) "The Chinese Approach to Capital Inflows: Patterns and possible explanations", NBER Working Paper No. 11306.

Sakurai, N. (1990), 'Methodology of Multisectoral Growth Decomposition Models: A survey and Extensions", OECD Discussion Paper No. 1.

Eurostat (2008), "Eurostat Manual of Supply, Use and Input-Output Tables", Methodologies and Working Papers (Luxembourg, Eurostat).

WIOD (World Input-Output Database): http://www.wiod.org/new_site/home.htm.

Wong, Christine (2011), "The Fiscal Stimulus Programme and Public Governance Issues in China", OECD Journal on Budgeting, Vol. 11/3.

World Bank (2015) “China Economic Update”, World Bank Office, Beijing, No. 97901. 
World Bank (2014) “China Economic Update”, World Bank Office, Beijing, No. 88538.

World Bank (2005) "China Integration of National Product and Factor Markets Economic Benefits and Policy Recommendations”, World Bank Report No. 31973-CHA.

Wyckoff, A. and Sakurai, N. (1992), 'Structural Change and Industrial Performance', OECD Documents, OECD, Paris.

Yang, C., Dietzenbacher, E., Pei. J., Chen, X., Zhu K. \& Tang Z. (2015) "Processing Trade Biases. The Measurement of Vertical Specialization in China", Economic Systems Research, Vol. 27, No 1, pp. 60-76.

Yueh, L. (2010) The Economy of China (Cheltenham, E.Elgar)

Yueh, L. (2011) Enterprising China. Business, Economic, and Legal Developments since 1979 (Oxford, Oxford University Press).

Yueh, L. (2013) China's Growth: The Making of an Economic Power (Oxford, Oxford Scholarship Online).

Zhang, X. and Tan, K. (2007) "Incremental Reform and Distortions in China's Product and Factor Markets", The World Bank Economic Review, Vol. 21, No. 2, pp. 279-99.

Zhen, J., Bigsten, A. and Hu, A. (2009) "Can China's Growth be Sustained? A Productivity Perspective” World Development, Vol. 37, No. 4, pp 874-88.

Zheng, J., Wang, Z. and Shi, J (2008) "Industrial Productivity Performance in Chinese Regions (1987-2002): A Decomposition Approach”, Journal of Chinese Economic and Business Studies, Vol. 6, No. 2, 157-75. 


\section{Appendix}

\section{A. Decomposition of Output Change}

The decomposition of gross output change, i.e. absolute growth and the growth rate, between two periods amounts to calculating the first difference of equation (8). That is:

$\Delta X=\Delta(B G)=B_{0} \Delta G+\Delta B G_{0}+\Delta B \Delta G$

Either the first or the second term on the right-hand side can absorb the third term. If the second term absorbs the third, then the calculation will be weighted by the initial year of the structural $B$ matrix and the final year of the volume $G$ matrix, and vice versa if the third term is absorbed by the first term. This is similar to Laspeyres and Paasche index weightings, respectively, i.e.
$\Delta X=B_{0} \Delta G+\Delta B G_{1}$
(Laspeyres weighting)
$\Delta X=B_{1} \Delta G+\Delta B G_{0}$
(Paasche weighting)

The numerical results from the two alternative weightings are not normally equivalent and can be very different if the third term is large. To correct this index number problem, several methods have been devised, such as re-weighting the terms, creating an appropriate divisia index, etc. However, a simpler method that distributes the third term proportionally into the other two terms is by taking the simple arithmetical average of the Laspeyres and Paasche results. This appears to produce a good approximation, as analyzed by Dietzenbacher and Los (1998). This method has also been used by Chenery and Syrquin (1986) and Wyckoff and Sakurai (1992). We also use it here for all our actual calculations. However, the derivation of the formula for either alternative is analogous, so for presentational purpose only we use the Laspeyres weighting, i.e. letting the 
third term be absorbed by the second term. The two terms on the right-hand side of equation (10) can be decomposed as:

$$
B_{0} \Delta G=B_{0}\left(U_{0}^{F} * \Delta F+\Delta E+U_{0}^{F} * F_{1}\right)^{(12)}
$$

and

$$
\Delta B G_{1}=B_{0}\left(\Delta U^{W} * W_{1} i+U_{0}^{W} * \Delta A X_{1}\right)^{(13)}
$$

Therefore, the total decomposition for the absolute growth or variation in gross output will be:

$$
\Delta X=B_{0} U_{0}^{F} * \Delta F+B_{0} \Delta E+B_{0} \Delta U^{F} * F_{1}+B_{0} \Delta U^{W} * W_{1} i+B_{0} U_{0}^{W} * \Delta A X_{1}
$$

The decomposition for the gross output growth rate can be obtained by dividing equation (14) by $X_{0}$. Each of the five terms on the right-hand side of (14), in variation or growth rate terms, represents the direct and indirect contribution to the gross output of the economy.

\section{B. Decomposition of Output Share Changes}

The share change for the $i^{\text {th }}$ industry is simply the difference between the gross output share of the terminal year $\left(S_{i 1}\right)$ minus that of the base year $\left(S_{i 0}\right)$ :

$$
\Delta S_{i}=S_{i 1}-S_{i 0}=X_{i 1} / X_{t 1}-X_{i 0} / X_{t 0}
$$

Where $i: 1, \ldots, n$ (n industries) and subscript $t$ denotes "total". Let us first define the following:

$$
X_{i 1}=X_{i 0}\left(1+g_{i}\right) \text { and } X_{t 1}=X_{t 0}\left(1+g_{a}\right)
$$

Where $g_{i}$ and $g_{a}$ denote the gross output growth rate for the $i^{\text {th }}$ industry and the economy's average gross output growth rate, respectively. Replacing $X_{t 0}$ with $X_{t 1} /\left(1+g_{a}\right)$ in (15) and manipulating yields:

$$
\Delta S_{i}=\left[X_{i 1}-\left(1+g_{a}\right) X_{i 0}\right] / X_{t 1}
$$

Or to carry less notation, let $\delta X_{i}=\left[X_{i 1}-\left(1+g_{a}\right) X_{i 0}\right]$, then: 


$$
\Delta S_{i}=\delta X_{i} / X_{t 1}
$$

The numerator, $\delta X_{i}$, contains the difference between the actual value of $X_{i}$ in the terminal year and the value of $X_{i}$ that would have occurred had it grown at the economy's average growth rate $\left(g_{a}\right)$ over the period. Therefore, the equation represents the deviation of each industry's gross output from balanced growth, normalized by the actual value of the gross output in the terminal year. This allows us to derive the decomposition formula in a closely analogous way to (10) above. In matrix form, the case of Laspeyres weighting yields:

$\delta X=B_{0} \delta G+\Delta B G_{1}$

While the Paasche weighting leads to:

$\delta X=B_{1} \delta G+\Delta B G_{0}\left(1+g_{a}\right)$

Notice that only the volumes of the base year appear multiplied by the coefficient $\left(1+g_{a}\right)$, in the latter weighting. As before, given that the derivation of the formula is analogous for both cases, for presentational purpose only, we use the Laysperes derivation below. Therefore, applying the same solving procedure as before we obtain ${ }^{(14)}$ :

$\delta X=B_{0} \hat{\mathrm{U}}_{0}^{\mathrm{F}} * \delta F+B_{0} \delta E+B_{0} \Delta \hat{\mathrm{U}}_{0}^{\mathrm{F}} * F_{1}+B_{0} \Delta \hat{\mathrm{U}}_{0}^{\mathrm{W}} * W_{1} i+B_{0} \hat{\mathrm{U}}_{0}^{\mathrm{W}} * \Delta A X_{1}$

Notice that the last three terms on the right-hand side are the same as in equation (14) above. Dividing equation (21) by $X_{t 1}$ we are back to equation (18), but in matrix form. The meaning is analogous to equation (14), but refers to the absolute value of the share change $(\delta X)$ and the relative share change in percentage points $\left(\delta X / X_{t 1}\right)$, rather than the absolute growth $(\Delta X)$ and its growth rate $\left(X^{-1} \Delta X\right)$. 


\section{FIGURES: TABLES (2), CHARTS (2) AND GRAPHS (6)}

Table No.1: Share Changes (percentage points) and Growth Rates (\%): 1995-2010

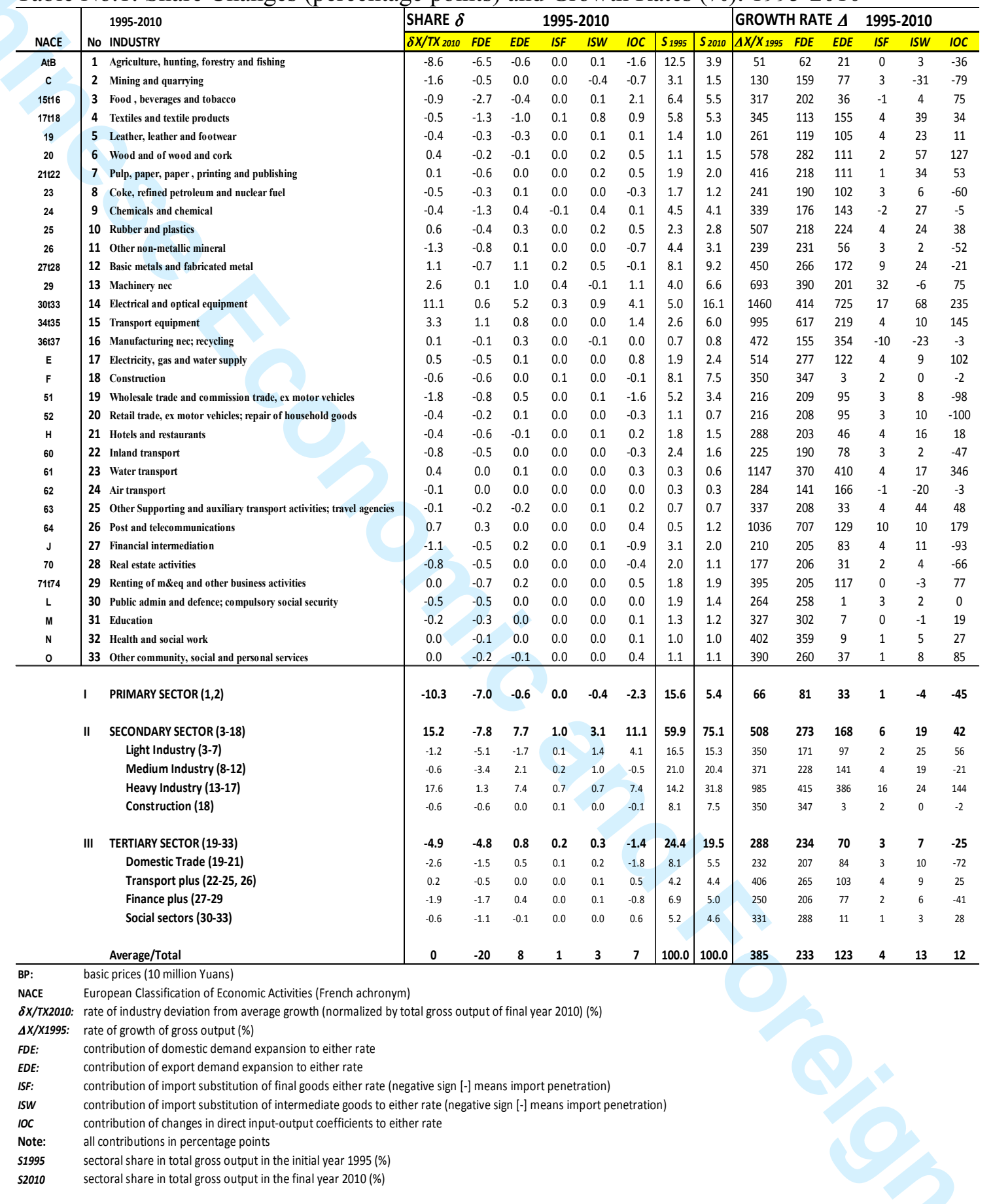




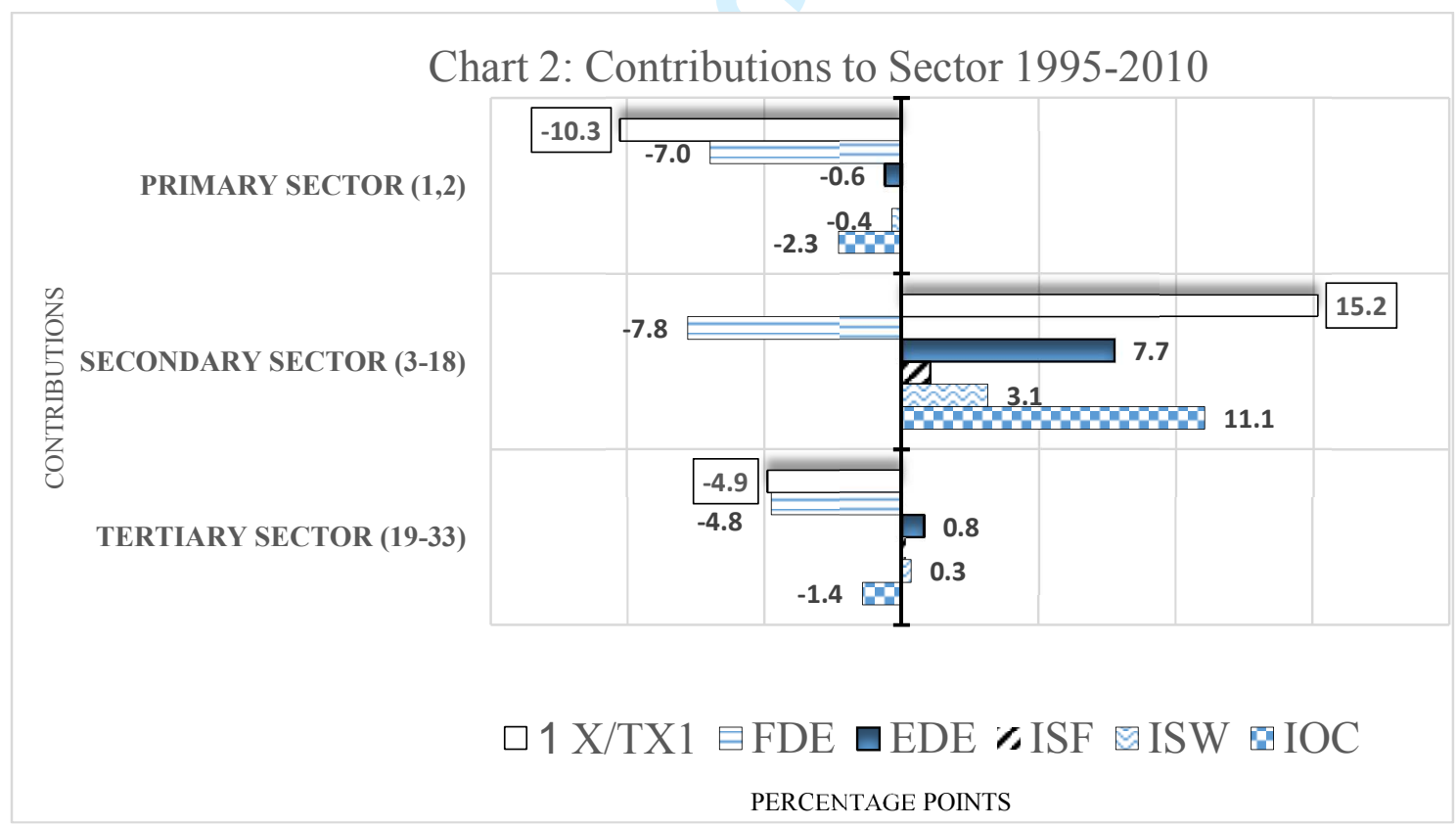

dX/TX1: total share change, composed of the following contributions $\rightarrow$ FDE: domestic demand, EDE: export demand, ISF: import substitution of final goods, ISW: import substitution of intermediate goods and IOC: input-output coefficients. The sum of these contributions is equal to the total share change. 
Graph 1: Growth Trajectory of Economy over 1995-2011

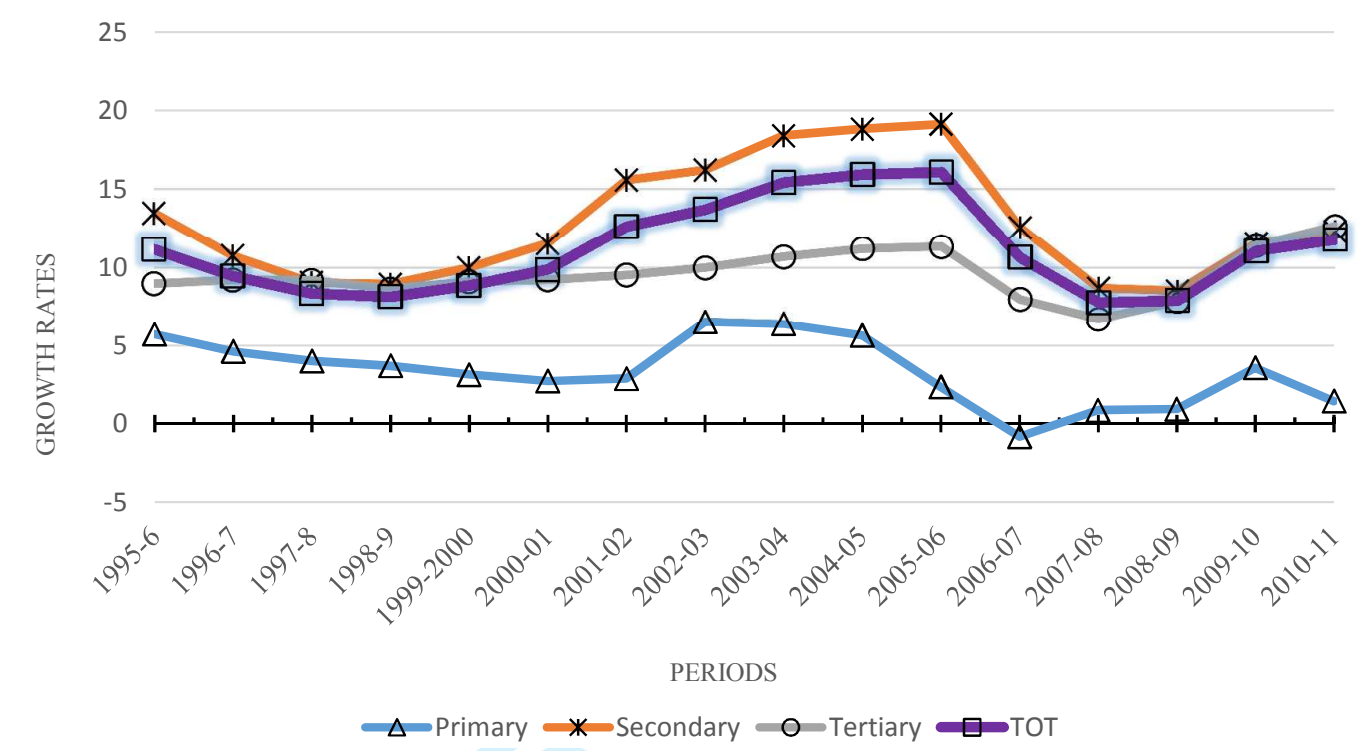

Graph 2: Sectoral Change over 1995-2011

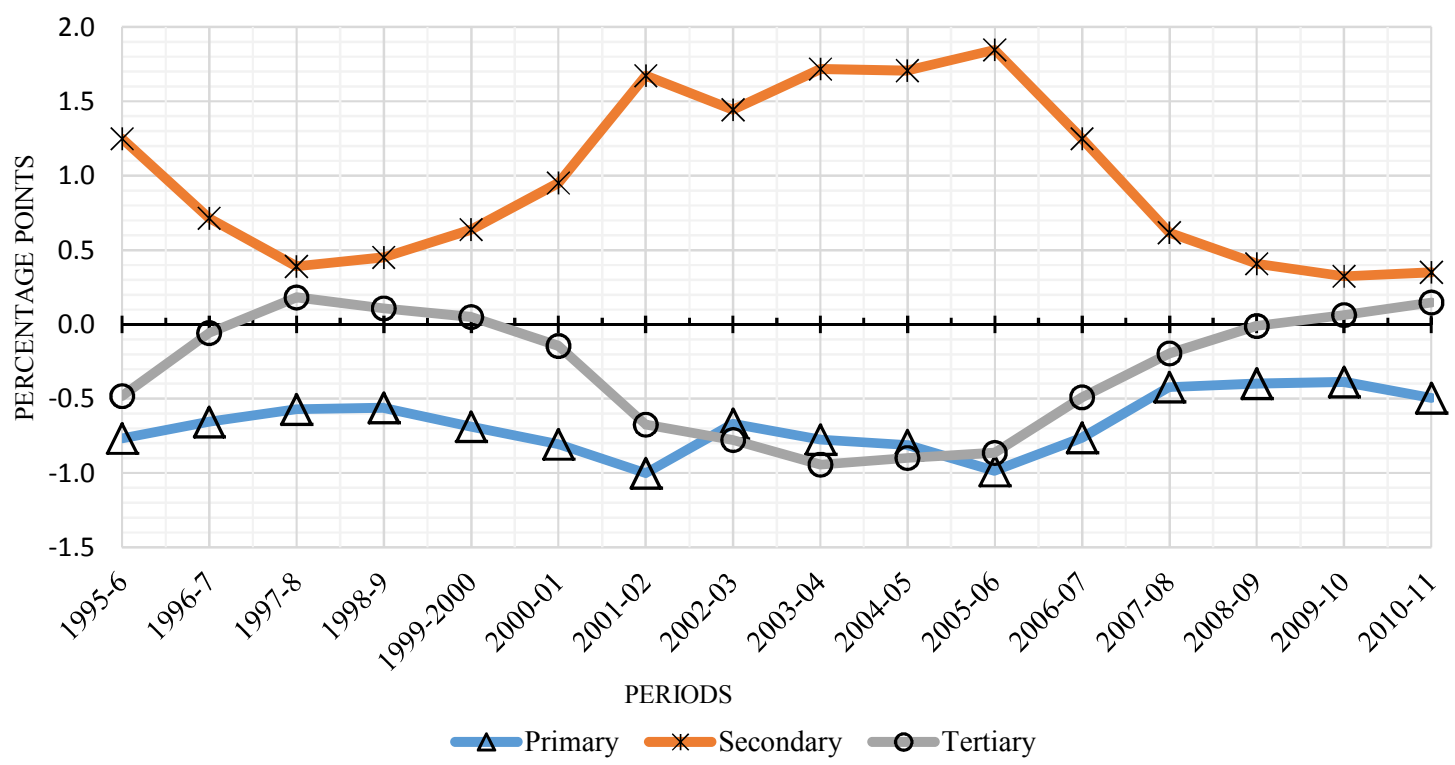


Graph 3: Secondary Sector and its Main Subsectors over 1995-2011
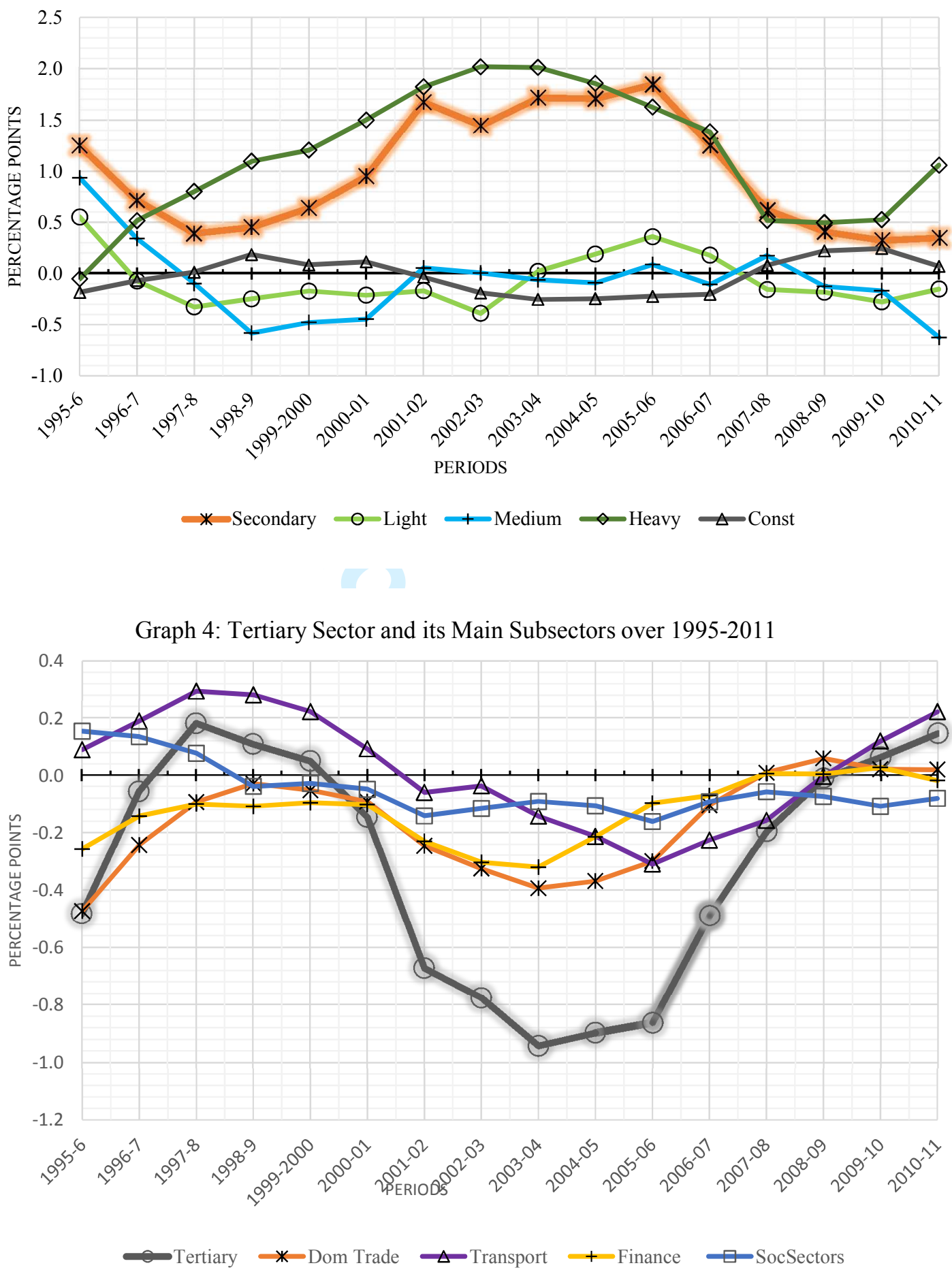
Graph 5: Trajectory of Contributions over 1995-2010

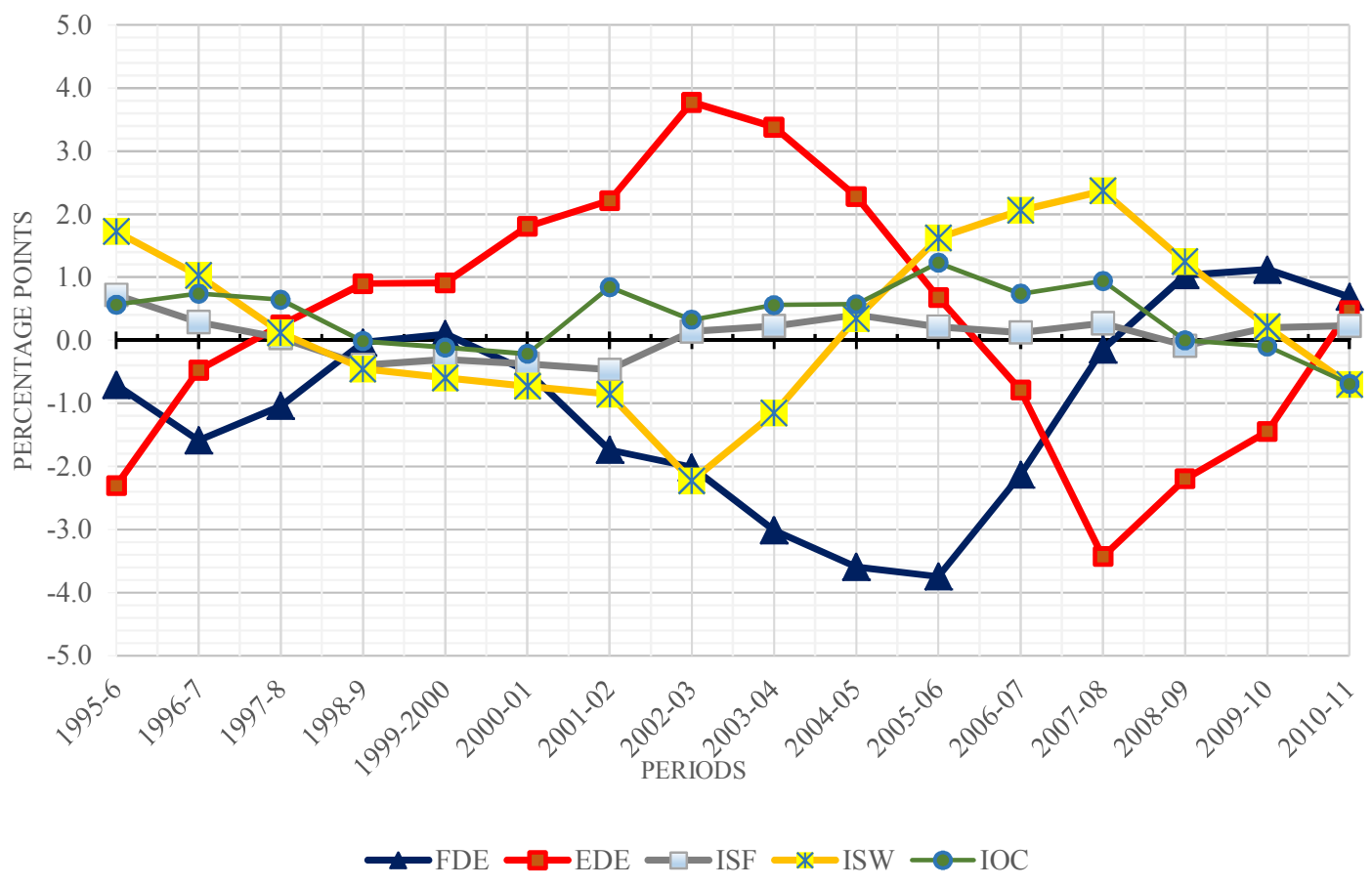




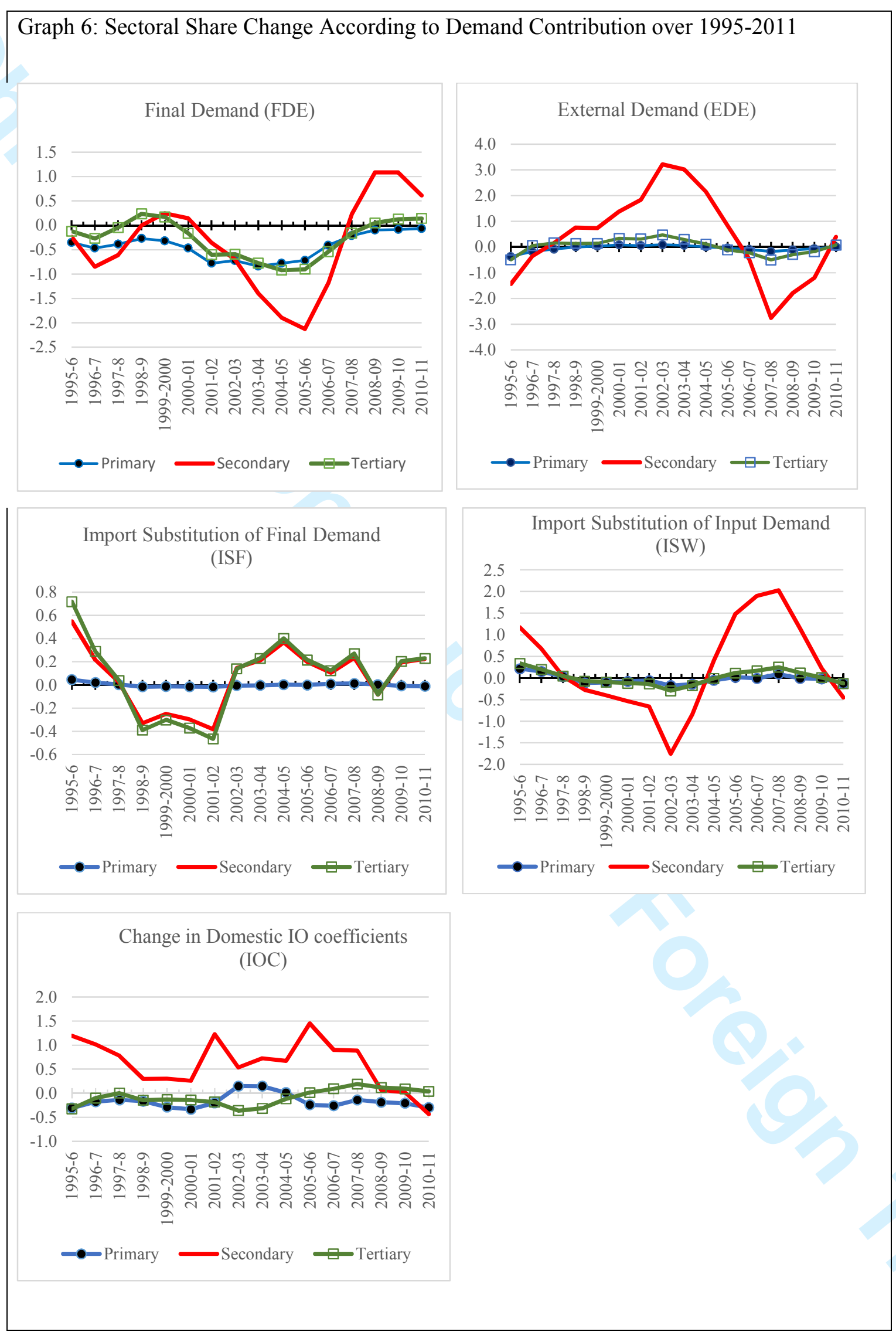


Table No.2: Phases, Shocks, Policies, and Graphs Visualization

\begin{tabular}{|c|c|c|c|c|c|}
\hline PERIOD & WORLD & POLICIES & ECONOMIC EFFECT & SECTOR & Graph \\
\hline 1994-1996 & "normal" & liberalization, privatization & lagged & to take hold & 2 \\
\hline $1997-2001$ & 1997 Asian crisis & $\begin{array}{l}\text { domestic stimulus } \\
\text { freeing of prices } \\
\text { WTO membership } \\
\text { Trade agreements }\end{array}$ & slowdown & all sectors & $2,5,6$ \\
\hline 2001-2006 & "normal" & deepening reform policies & strong acceleration & secondary & $2,3,5$ \\
\hline $\begin{array}{l}2006-2007 \\
2007-2009 \\
2009-2011\end{array}$ & $\begin{array}{l}\text { onset world recession } \\
\text { world recession } \\
\text { world recession }\end{array}$ & $\begin{array}{l}\text { recognition of huge imbalances } \\
\text { massive domestic stimulus } \\
\text { massive domestic stimulus }\end{array}$ & $\begin{array}{l}\text { significant deceleration } \\
\text { bottoming out } \\
\text { recovery }\end{array}$ & $\begin{array}{l}\text { all sectors } \\
\text { sectoral reversal } \\
\text { back reversal? }\end{array}$ & $\begin{array}{l}2,3,5 \\
2,5,6 \\
2,5,6\end{array}$ \\
\hline
\end{tabular}


Title: Structural Change in Industrial Output: China 1995-2010

Author: J.M. Albala-Bertrand

Contact Address: J.M. Albala-Bertrand. School of Economics and Finance, Queen Mary, University of London, Mile End Road, London E1 4NS, E-Mail: J.M.AlbalaBertrand@qmul.ac.uk, Tel: +44(0)20 7882 5094, Fax: 02089833580.

Contact Address: Dr J.M. Albala-Bertrand. School of Economics and Finance, Queen Mary, University of London, Mile End Road, London E1 4NS, E-Mail: J.M.Albala-Bertrand@qmul.ac.uk, Tel: +44(0)20 7 882 5094, Fax: 0208983 3580, 